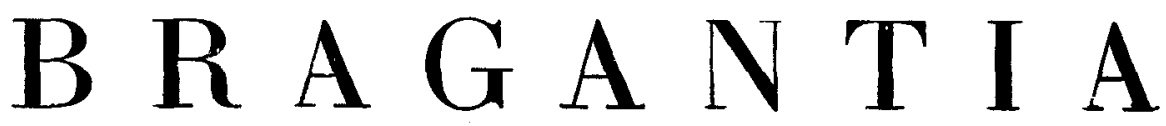

Boletim Científico do Instituto Agronômico do Estado de S. Paulo

Vol. 29

Campinas, maio de 1970

N. ${ }^{\circ} 17$

\title{
MORFOLOGIA E ASPECTOS INTRACELULARES DO VIRUS LATENTE DA COUVE (1)
}

E. W. Kitajima, engenheiro-agrônomo, I. J. B. Camargo, biologista, e A. S. Costa, engenheiro-agrônomo, Seção de Virologia, Instituto Agronômico ${ }^{(2)}$

\section{SINOPSE}

Partículas alongadas de $15 \mathrm{~m} \mu$ de diâmetro e $650 \mathrm{~m} \mu$ de comprimento normal foram consistentemente detectadas em exames electrono-microscópicos de preparações "leaf dip" de 6 espécies diferentes de plantas infetadas pelo vírus latente da couve (Brassica oleracea L. var. aeephala) (VLC). Tais partículas são consideradas como sendo de um vírus que poderia ser incluído no grupo do vírus $\mathbf{S}$ da batata, na classificação dos vírus alongados de Brandes.

Exames de secções ultrafinas de tecidos foliar e radicular de couve infetada pelo VLC, demonstraram a ocorrência do VLC, formando agregados mais ou menos organizados no citoplasma. Não se notou alterações citológicas sensíveis como conseqüência da infecção, o que está de acôrdo com a ausência de sintomas externos em couve infetada pelo VLC.

:av

\section{1 - INTRODUÇÃO}

Durante investigações sôbre a suscetibilidade de variedades de couve (Brassica oleracea L. var. acephala) ao vírus do mosaico do nabo ( = vírus da mancha anular preta do repôlho), verificou-se que tôdas as variedades em estudo estavam infetacas por um vírus latente. Ėste vírus, denominado de latente da couve (VLC), é transmissivel mecânicamente e por afídeos a várias plantas testes (Costa, dados não publicados).

(1) Êste trabalho recebeu subvençôes da FAPESP (C. Agron. 69/879 e 70/076), do CNPq (TC 12275) e do convênio CAPES/BID/BNDE. Recebido para publicação em 25 de março de 1970.

( $\left.{ }^{2}\right)$ Bolsistas do CNPq. 
Êste trabalho relata os resultados das investigações realizadas a fim de estabelecer a morfologia do VLC. Alguns aspectos intracelulares do VLC acham-se também descritos.

\section{2 - MATERIAL E MÊTODOS}

Virus e hospedeiras - Utilizou-se um isolado do VLC, mantido na coleção da Seção de Virologia, do Instituto Agronômico. O material para estudo foi obtido de plantas, mecânicamente inoculadas pelo VLC, das hospedeiras: couve- $\mathrm{s}\left({ }^{3}\right)$; Chenopodium amaranticolor Coste \& Reyn.- Il; mostarda (Brassica alba Boiss. Rabenh.)- s; rabanete (Raphanus sativus L.)-s; perpétua (Gomphrena globosa L.)- 11 ; feijoeiro (Phaseolus vulgaris L.)- 11.

Métodos para microscopia electrônica - A morfologia do VLC foi investigada em preparaçōes rápidas para microscopia electrônica, obtidas a partir de fragmentos de fôlhas de plantas infetadas, utilizando-se o método de "leaf dip" de Brandes (3) ou combinando-o com a técnica de contrastação negativa (8). As partículas encontradas foram fotografadas, sendo elas medidas a uma magnificação final de $50.000 \mathrm{x}$. Os comprimentos determinados foram distribuídos em classes de $25 \mathrm{~m} \mu$ de intervalo. Preparações similares foram feitas de plantas de rabanete, mostarda, perpétua e couve chinesa (Brassica chinensis L.) infetadas pelo vírus do mosaico do nabo (VMN), cujas partículas têm comprimento normal já estabelecido, sendo seu valor $750 \mathrm{~m} \mu$ (1). Partículas do VMN foram fotografadas e medidas em condiçóes comparativas com as do VLC para servirem de calibrador. Como contrôle, preparações feitas de plantas sadias, não inoculadas, foram também examinadas.

Para histologia electrono-microscópica, pequenos fragmentos foliares, ou ponta de raíz, de couve sadia ou infetada pelo VLC, foram fixados em uma solução de $\mathrm{OsO}_{4}$ a $1 \%$ em tampão de fosfato de sódio $0,2 \mathrm{M}$, pH 7 , durante $12-18$ horas a $4^{\circ} \mathrm{C}$ (14). Após a desidratação em acetona, os tecidos foram incluídos em Fpon (12). Os blocos foram seccionados em ultramicrótomo Porter-Blum, tendo sido as secções contrastadas com sais de chumbo e uranila $(16,19)$ antes de serem examinadas em microscópio electrônico Elmiskop I, da Siemens.

${ }^{3}$ ) s- invasāo sistêmica; 11- lesões locais. 


\section{3 - RESULTADOS}

Morfologia do vírus - Em preparações rápidas ("leaf dip" convencional ou combinada com contrastação negativa), feitas de plantas de 6 espécies diferentes, infetadas pelo VLC, uma quantidade apreciável de partículas alongadas, algo rígidas, de $15 \mathrm{~m} \mu$ de diâmetro, foram observadas ao microscópio electrônico

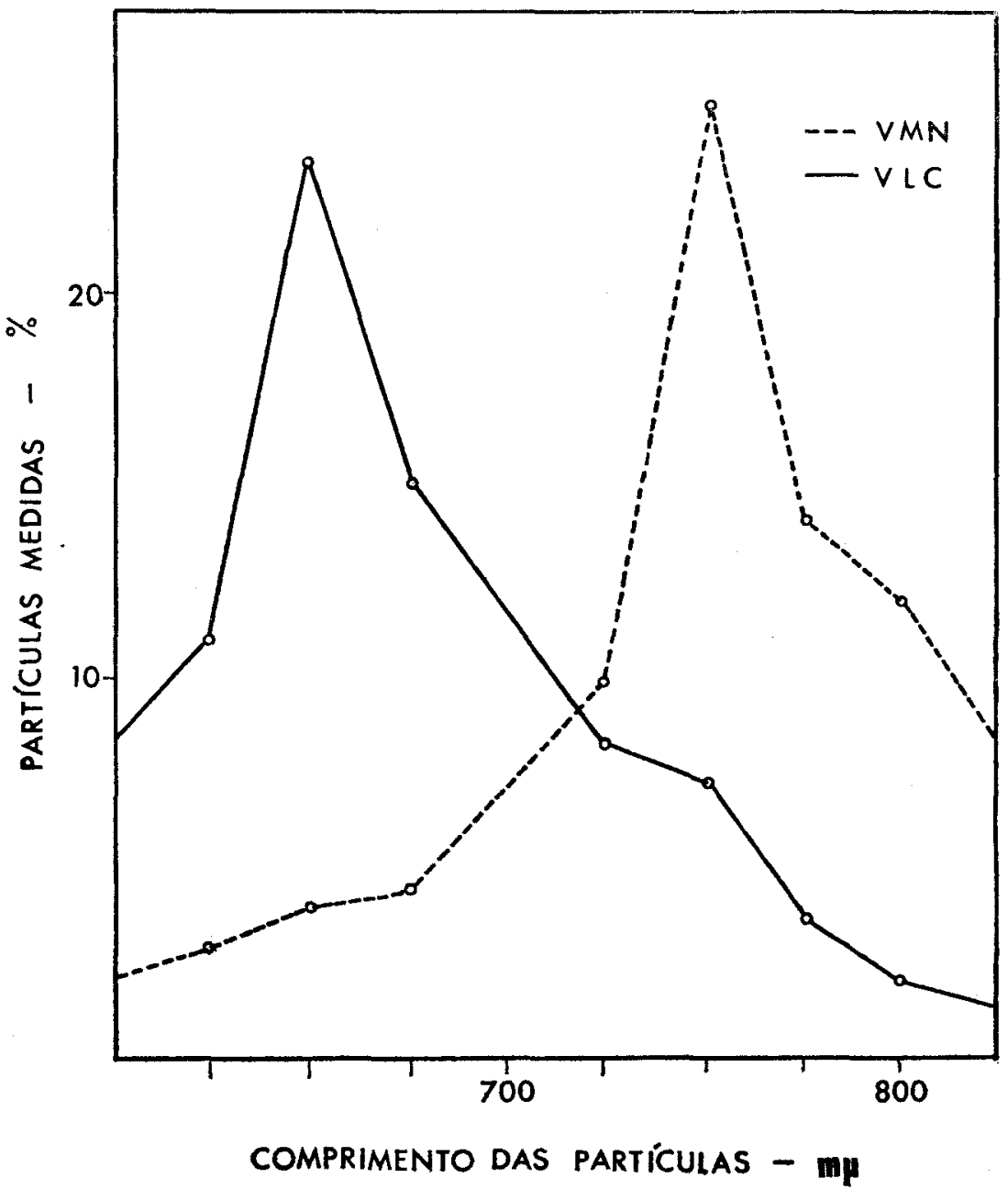

Figura 1. - Curvas de distribuição dos comprimentos das particulas dos virug latente da couve (VLC) e do mosaico do nabo (VMN), presentes em preparações "leaf dip", medidos em condiçŏes comparativas. 
(estampa $1 A$ e $B$ ). O histograma da distribuição dos comprimentos dessas partículas mostrou a existência de uma classe modal a $650 \mathrm{~m} \mu$, que com as classes adjacentes formava um pico proeminente neste histograma (figura 1).

QUUADRO 1. - Resultados das medições comparativas entre o virus latente da couve e o vírus do mosaico do nabo, em preparações feitas pelo método de "leaf dip"

\begin{tabular}{|c|c|c|c|}
\hline $\begin{array}{c}\text { Número } \\
\text { do } \\
\text { experimento }\end{array}$ & Planta hospedeira & Vírus $\left({ }^{1}\right)$ & $\begin{array}{l}\text { Comprimento } \\
\text { normal } \\
(\mathrm{mp})\end{array}$ \\
\hline $1 \ldots \ldots \ldots$ & Chenopodium amaranticolor & VLC & 655 \\
\hline & Rabanete (Raphanus sativus) $\ldots \ldots \ldots$ & VMN & 755 \\
\hline $2 \ldots \ldots \ldots$ & Chenopodium amaranticolor .... & VLC & 677 \\
\hline & Mostarda (Brassica alba) $\ldots \ldots \ldots \ldots \ldots$ & VMN & 770 \\
\hline $3 \ldots \ldots \ldots$ & $\begin{array}{l}\text { Chenopodium amaranticolor } \ldots \ldots \ldots \ldots \\
\text { Couve chinesa (Brassica chinensis) } \ldots\end{array}$ & $\begin{array}{l}\text { VLC } \\
\text { VMN }\end{array}$ & $\begin{array}{l}657 \\
760\end{array}$ \\
\hline $4 \ldots \ldots \ldots$ & 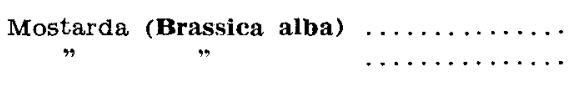 & $\begin{array}{l}\text { VLC } \\
\text { VMN }\end{array}$ & $\begin{array}{l}657 \\
747\end{array}$ \\
\hline $5 \ldots \ldots \ldots$ & $\begin{array}{c}\text { Rabanete (Raphanus sativus) } \\
\ldots \\
\end{array}$ & $\begin{array}{l}\text { VLC } \\
\text { VMN }\end{array}$ & $\begin{array}{l}660 \\
747\end{array}$ \\
\hline 6 & Gomphrena globosa $\ldots \ldots \ldots \ldots \ldots \ldots \ldots \ldots$ & $\begin{array}{l}\text { VLC } \\
\text { VMN }\end{array}$ & $\begin{array}{l}658 \\
753\end{array}$ \\
\hline$\cdots \cdots$ & $\begin{array}{l}\text { Feijoeiro (Phaseolus vulgaris) } \ldots \ldots \ldots \\
\text { Couve (Brassica oleracea var. acephala) }\end{array}$ & $\begin{array}{l}\text { VLC } \\
\text { VLC }\end{array}$ & $\begin{array}{l}650 \\
648\end{array}$ \\
\hline
\end{tabular}

(1) $\mathrm{VLC}=$ virus latente da couve; $\mathrm{VMN}=$ vírus do mosaico do nabo.

O comprimento normal (CN) destas partículas determinado com base no histograma (4) foi de $654 \mathrm{~m} \mu$, tendo sido medidas 1290 partículas. A fim de ter maior segurança nas medições, várias micrografias electrônicas do VLC e do VMN foram tiradas em condições comparativas. Os resultados podem ser apreciados na figura 1 e no quadro 1 . O CN do VMN foi de $755 \mathrm{m \mu}$, considerando-se o total de 6 medições, e do VLC, $656 \mathrm{~m} \mu$, obtido nas mesmas condições. Notou-se um paralelismo na variação dos CN determinados, i.e., sempre que o valor do $\mathrm{CN}$ do VMN era maior ou menor que a média o CN do VLC flutuou no mesmo sentido, em relação à média (quadro 1 ). 
Nas preparações contrastadas negativamente, as partículas do VILC apareciam como partículas alongadas e maciças, sem revelar detalhes internos (estampa 1 B).

Em preparações similares, obtidas de plantas não inoculadas (contrôles), não se constatou em nenhum caso a presença de partículas similares às acima citadas.

Exame de secções ultrafinas - Secções ultrafinas, tanto do tecido foliar como do radicular de couve infetada pelo VLC, quando examinadas ao microscópio electrônico não revelaram nenhuma alteração marcante, em relação aos tecidos de plantas não inoculadas. Todavia, verificou-se constante ocorrência de agregados de partículas alongadas, no citoplasma das células de plantas infetadas (estampas 2-5). As partículas componentes de tais agregados eram aparentemente rígidas, com 10-15 mu de diametro e comprimento variável, conforme o plano de secção, e são consideradas como representando o VLC in situ. Sua localização no citoplasma era variável, não se achando especìficamente associada a determinados orgânulos celulares, embora com certa frequiência as partículas se achassem nas proximidades de cloroplastos (estampas $2 B, 5 A-B$ ). Todavia, esta situação parece refletir os resultados dos movimentos citoplasmáticos, que fariam as partículas tenderem a se acumular nas proximidades de obstáculos que se antepusessem ao fluxo citoplasmático. A forma $\mathrm{e}$ as dimensões dos agregados de partículas do VLC eram variáveis e naturalmente dependeriam do plano pelo qual êles foram seccionados. A disposição das partículas dentro do agregado normalmente era a de estar com seus eixos maiores paralelos. Quando a secção era paralela a êste eixo maior, notava-se freqüentemente que as partículas apresentavam suas extremidades num mesmo plano, podendo dois ou mais de tais conjuntos aparecerem sobrepostos, mas separados ligeiramente uns dos outros, formando configurações que lembram a disposição das miofibrilas num músculo estriado (estampas $2 A, 4 C$ e $5 B$.), O comprimento dessas partículas era aproximadamente igual ao do CN das particulas alongadas encontradas em preparações "leaf dip". Às vêzes, as partículas componentes das inclusões apresentavam-se bastante longas, provàvelmente devido a uma agregaçāo terminal de partículas menores. Em certas inclusões, as partículas formavam um arranjo em espiral de tal modo que uma partícula, embora paralela a outra, tinha seu eixo ligeiramente inclinado, em relação à partícula vizinha. Os exemplos ilustrados na estampa 3 mostram tal arranjo em espiral. As particulas na região central 
cả inclusão acham-se perpendiculares ao plano de secção, e, à medida que se vai à periferia, o eixo maior das partículas vai tendendo a se tornar paralelo ao plano de secção.

No tecido radicular, agregados similares aos constatados nas fôlhas foram também encontrados. Mas ocasionalmente observou-se grupos de partículas de diâmetro pouco maior que as anteriormente descritas, cujo valor oscilava entre 15-20 mi, as quais quando seccionadas transversalmente podiam exibir arranjo perfeitamente cristalino. Em secções longitudinais dessas partículas, mostrou-se que seu comprimento era também próximo ao do CN das partículas presentes nas preparações "leaf dip" (estampa 4).

Nas fôlhas, os agregados de VLC foram mais comumente encontrados no parênquima lacunoso e palisádico e menos freqüentes na epiderme e no parênquima vascular. Partículas não foram vistas no interior dos vasos crivados ou lenhosos maduros, muito embora formas imaturas dêstes vasos pudessem ocasionalniente conter agregados do vírus (estampa $2 B$ ).

$\mathrm{Na}$ ponta de raíz, grupos de partículas alongadas foram encontradas na epiderme, na coifa e na região cortical, mas näo na zona meristemática.

Em certas células foliares, pequenas áreas ricas em vesículas e ribosomas, e às vêzes contendo partículas do VLC individuais, puderam ser notadas. Nas suas proximidades, invariàvelmente, ocorriam agregados de VLC (estampa $5 A$ ).

Em tecidos de plantas de couve sadias, não inoculadas, em nenhum caso tais agregados puderam ser encontrados.

\section{4 - DISCUSSÃO}

As particulas alongadas presentes em preparaçōes "leaf dip" e aquelas observadas no interior dos tecidos foliares ou radiculares, formando comumente agregados paralelos ou em espiral, devem ser idênticas. Em certas inclusões intracelulares, particularmente, pôde-se notar que o comprimento das partículas que as constituiam era literalmente igual ao do $\mathrm{CN}$ determinado para as partículas das preparaçōes "leaf dip". O diâmetro das particulas in situ, geralmente, foi pouco inferior ao daquelas das preparações "leaf dip", mas a diferença pode ser perfeitamente 
atribuivel aos diferentes métodos de preparo, pois usualmente os métodos de coloração empregados em histologia electrono-microscópica evidenciam menos a capa protéica envoltória do vírus.

A natureza viral dessas partículas alongadas, notadas tanto em preparações "leaf dip" como no interior dos tecidos das plantas afetadas pelo VLC, pode ser inferida pela sua constante associação com o material infetado (plantas pertencentes a 6 espécies diferentes) e pela sua similaridade com outros vírus já descritos. Ensaios preliminares de purificação e infetividade têm comprovado esta inferência (Oliveira, Kitajima e Costa, clados não publicados). A morfologia das partículas permite incluir o VLC no grupo $\mathbf{S}$ da batata, na classificação dos vírus a.longados de Brandes (4). O próprio caráter latente do VLC em sua hospedeira natural, suas propriedades físicas in vitro, sua transmissibilidade por métodos mecânicos e por afídeos vectores (Costa, dados não publicados) mostram que o VLC compartilha também das características gerais dos componentes do grupo do virus $\mathrm{S}$ da batata. Todavia, os testes efetuados até o momento não permitiram estabelecer relações serológicas entre o VLC e outros vírus do grupo $\mathbf{S}$ da batata (Oliveira, dados não publicados ).

A configuração adquirida pelo VLC intracelularmente, em especial a espiralada, é idêntica àquela relatada para o vírus do mosaico amarelo do trevo, membro do grupo $X$ da batata (15). Fim relaçāo a outros componentes do grupo $\mathbf{S}$ da batata, o aspecto das células infetadas pelo VLC é pràticamente idêntico ao daquelas invadidas pelo vírus $\mathbf{S}$ da batata (Kitajima, dados não publicados), mas em relação aos vírus latente da Passiflora e um virus encontrado em lírio (Lilium longiflorum Thunb.) as descriçōes têm sido superficiais, não permitindo assim uma comparação efetiva com o VLC $(13,17)$.

A ocorrência de agregados de VLC na coifa e sua ausência na zona meristemática, em ponta de raíz, é um fato similar áo reiatado para o vírus de vira-cabeça (9). Tem-se sugerido que a presença de vírus na coifa seria indicativo de sua ocorrência no meristema, ainda que na forma não particulada (5). Todavia, excluindo a possibilidade de uma infecção na fase inicial da €mergência de uma raíz lateral, parece razoável considerar que o vírus poderia infetar a coifa, mesmo sem infetar o meristema, através de seu transporte pelas células corticais e da epiderme, que circundam a zona meristemática. 
A natureza dos grupos de partículas ligeiramente mais grossas que aquelas consideradas VLC, embora de comprimento similar, não se acha perfeitamente esclarecida. Talvez as mesmas explicações sugeridas para certas partículas grossas associadas à infecção pelo virus do mosaico comum do fumo, i.e., forma mais hidratada, precursora da particula madura ou agregado de proteina-X $(11,18)$, possam ser-lhes aplicáveis.

Tem-se sugerido que a presença de determinados tipos de inclusão serviria para diagnosticar o grupo morfológico a que pertence um dado vírus, como no caso das inclusões lamelares tipicamente associadas à infecção com os vírus do grupo $Y$ da batata (6). Todavia, tal conceito não deve necessàriamente ser generalizado, pois há casos como o das inclusões (agregados paralelos ou em espiral, das partículas) aqui descritas, que podem ser formadas por virus pertencentes a grupos morfológicos distintos (VLC, do grupo $\mathbf{S}$ da batata; virus do mosaico amarelo do trevo, do grupo $\mathrm{X}$ da batata). Por outro lado, dentro de um mesmo grupo, têm sido observados tipos diferentes de agregados de vírus, como $\mathrm{o}$ do vírus $\mathrm{X}$ da batata $(2,7)$, o do virus do mosaico amarelo do trevo (15) e o do vírus do mosaico comum da mandioca (10), todos pertencentes ao grupo $\mathrm{X}$ da batata.

Finalmente, nossas observações demonstraram a presença de agregados de virus em diversos tecidos de couve infetados pelo VLC, mas não se notou efeitos citopáticos nas células invadidas pelo virus, o que sugere um equilíbrio entre o metabolismo normal da célula e o mecanismo de sintese do virus.

PARTICLE MORPHOLOGY AND INTRACELLULAR BEHAVIOR OF COLE LATENT VIRUS

\section{SUMMARY}

Electron microscopic examination of leaf dip preparations made from cole (Brassica oleracea L. var. acephala), Chenopodium amaranticolor Coste \& Reyn., radish (Raphanus sativus L.), mustard (Brassica alba Boiss. Rabenh.), bean (Phaseolus vulgaris L.) and Gomphrena globosa $L$. plants infected with cole latente virus (CLV) demonstrated consistently the presence of slender rods. These particles, considered as CLV, were about $15 \mathrm{~m} \mu$ wide and $650 \mathrm{~m} \mu$ in normal length (NL). The NL was determined in a series of comparative measurements using turnip 
mosaic virus (NL $=750 \mathrm{~m} \mu$ ) as a standard. Morphological characteristics of $\mathrm{CLV}$ permit its inclusion in the potato virus $S$ group, in Brandes' system of classification of elongated plant viruses.

Thin section profiles of root and leaf tissues, from CLV-infected cole, showed the frequent occurrence of fibrillar aggregates in the cytoplasm. The particles component of these aggregates were identified as CLV in situ due to the constant association with the infection and their mophological similarities with the particles found in leaf dip preparations. CLV-particles appeared with their longer axis laying side-by-side within these aggregates, often forming a spiral arrangement. Vesiculated areas were occasionally seen in the cytoplasm, with virions in or around them. Virus particles were found in most of the examined cells, except within the tracheids and sieve tubes in the leaf, and within the meristematic zone, in th root. Besides these abnormalities, no other remarkable changes in normal cell structure could be noticed, in agreement with the lack of external symptoms.

\section{LITERATURA CITADA}

1. BODE, O. \& BRANDES, J. Elektronenmikroskopische Untersuchungen des Kohlrübenmosaik-Virus (Turnip mosaic virus). Phytopath. Z. 34:103-106, 1958.

2. BORGES, M. L. V. \& DAVID-FERREIRA, J. F. Comparative study of cell structure in Datura metel $L$. healthy and infected with potato virus $X$ or potato virus $Y$. Revta. Biol. 6:421-437, 1968.

3. BRANDES, J. Eine elektronenmikroskopische Schnellmethode zum Nachweis faden-und stäbchenformiger viren, insbesondere in Kartoffeldunkelkeimen. NachrBl. dt. PflSchutzdienst, Braunschweig, 9:151-152, 1957.

4. - Identifizierung von gestreckten Pflanzen pathogen Viren auf morfologischer Grundlage. Mitt. biol. Bundesanstalt, Berlin-Dahlem, 110. 1964. 130p.

5. DE ZOETEN, G. A. \& SCHLEGEL, D. E. Nucleolar and cytoplasmic uridine- $\mathrm{H}^{3}$ incorporation in virus infected plants. Virology $32: 416-427,1967$.

6. EDWARDSON, J. R. Cylindrical inclusions in the cytoplasm of leaf cells infected with tobacco etch virus. Science 153:883-884, 1964.

7. KIKUMOTO, T. \& MATSUI, C. Electron microscopy of intracellular potato virus X. I. Virology 13:294-299, 1961.

8. KITAJIMA, E. W. A rapid method to detect particles of some spherical plant viruses in fresh preparations. J. Electronmicroscopy, Tokyo, 14:119-121, 1965. 
9. KITAJIMA, E. W. Electron microscopy of vira-cabeça virus (Brazilian tomato spotted wilt virus) within host cell. Virology 26:89-99, 1965.

10. \& COSTA, A. S. Microscopia electrônica de tecidos foliares de mandioca infetados pelo vírus do mosaico comum da mandioca. Bragantia 25:XXIII-XXVIII, 1966. Nota 6.

11. KOHLEMAINEN, L.; ZECH, H. \& WETTSTEIN, D. VON. The structure of cells during tobacco mosaic reproduction. Nesophyll cells containing virus crystals. J. Cell Biol. 25 (part 2): 77-97, 1965.

12. LUFT, J. H. Improvements in epoxy resin embedding methods. J. biophys. biochem. Cytol. 9:409-414, 1961.

13. LYONS, A. R. \& ALLEN JR., T. C. Electron microscopy of viruslike particles associated with necrotic fleck of Lilium longiflorum. J. Ultrastruct. Res. 27:198-204, 1969.

14. MILLONING, G. Studio sui fattori che determinano la preservazione della ultrastruttura. In: Buffa, P., ed. From molecule to cell. Symposia on Electron Microscopy. Roma, C. N. R. 1964. p.347-362.

15. PURCIFULL, D. E.; EDWARDSON, J. R. \& CHTISTIE, R. G. Electron microscopy of intracellular aggregates in pea (Pisum sativum) infected with clover yellow mosaic virus. Virology 29:276-284, 1966.

16. REYNOLDS, E. $\mathrm{S}$. The use of lead citrate at higt $\mathrm{pH}$ as an electron opaque stain in electron microscopy. J. Cell Biol. $17: 208-211,1963$.

17. SCHNEPF, E. \& BRANDES, J. Uber ein Virus aus Passiflora spec. Phytopath. Z. 43:102-105, 1961/62.

18. SHALLA, T. A. Assembly and aggregation of tobacco mosaic virus in tomato leaflets. J. Cell Biol. 21:253-264, 1964.

19. WATSON, M. L. Staining of tissue sections for electron microscopy with heavy metals. J. biophys. biochem. Cytol. 4:475-478, 1958. 


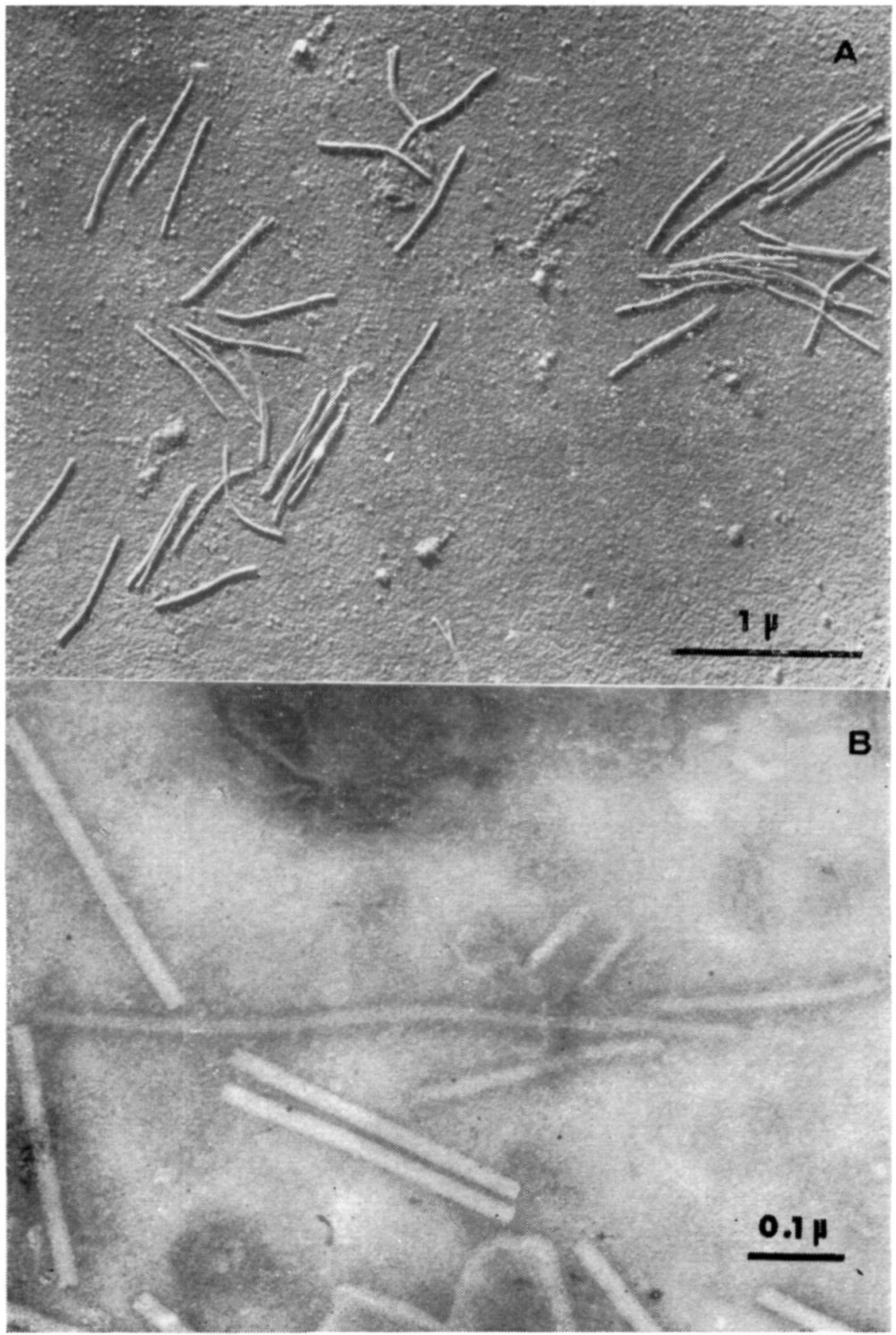

A - Partículas do vírus latente da couve (VLC) em preparações "leaf dip", metalizadas com cromo. B - Preparação contrastada negativamente com ácido fosfotúngstico, com partículas do VLC (longas e delgadas) e do virus do mosaico do fumo (curtas e grossas). Estas últimas servem como calibrador interno. 


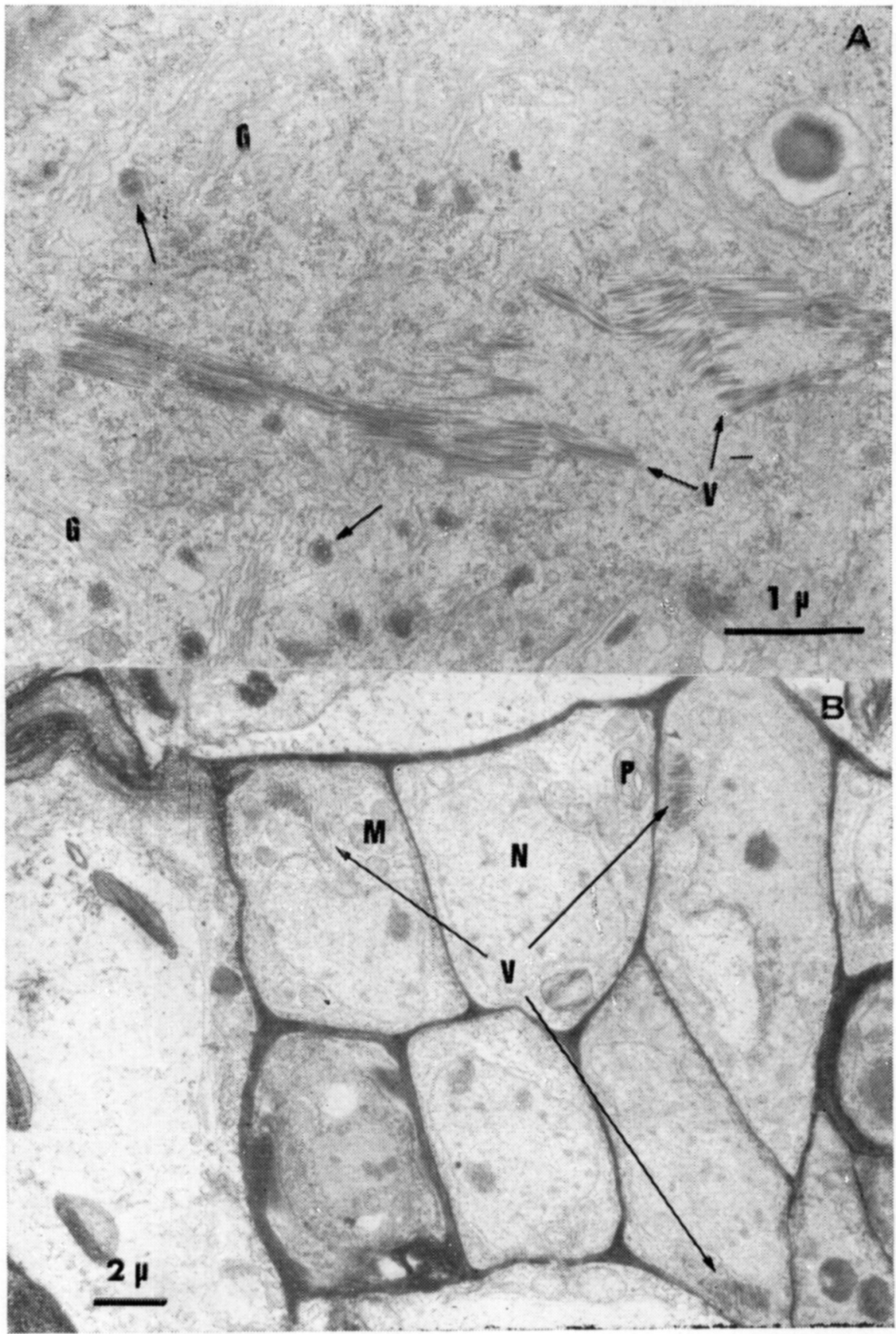

A - Vista parcial de uma cécula da coifa. Note-se que as partículas do VLC (V) têm comprimento relativamente uniforme. O complexo de Golgi (G) acha-se ativamente envolvido na secreção de substâncias mucilaginosas (setas). B - Micrografia electrônica de secçẩo ultra-fina de tecido foliar de couve, infetado pelo VLC, mostrando parte da região vascular, não diferenciada. Massas do virus (V) podem ser vistas em diversas células. $\mathbf{P}$ - cloroplastos; II - mitocôndrio; $\quad \mathbf{N}$ - núcleo, 


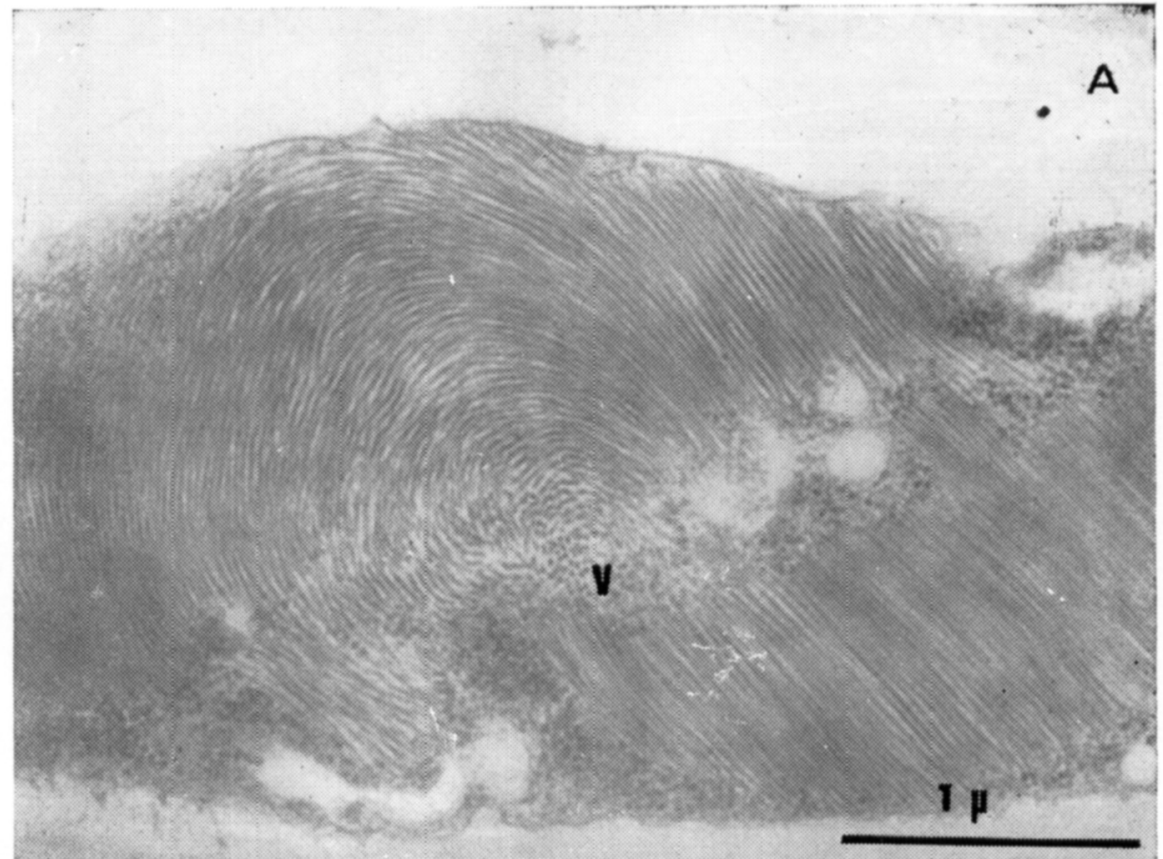

B

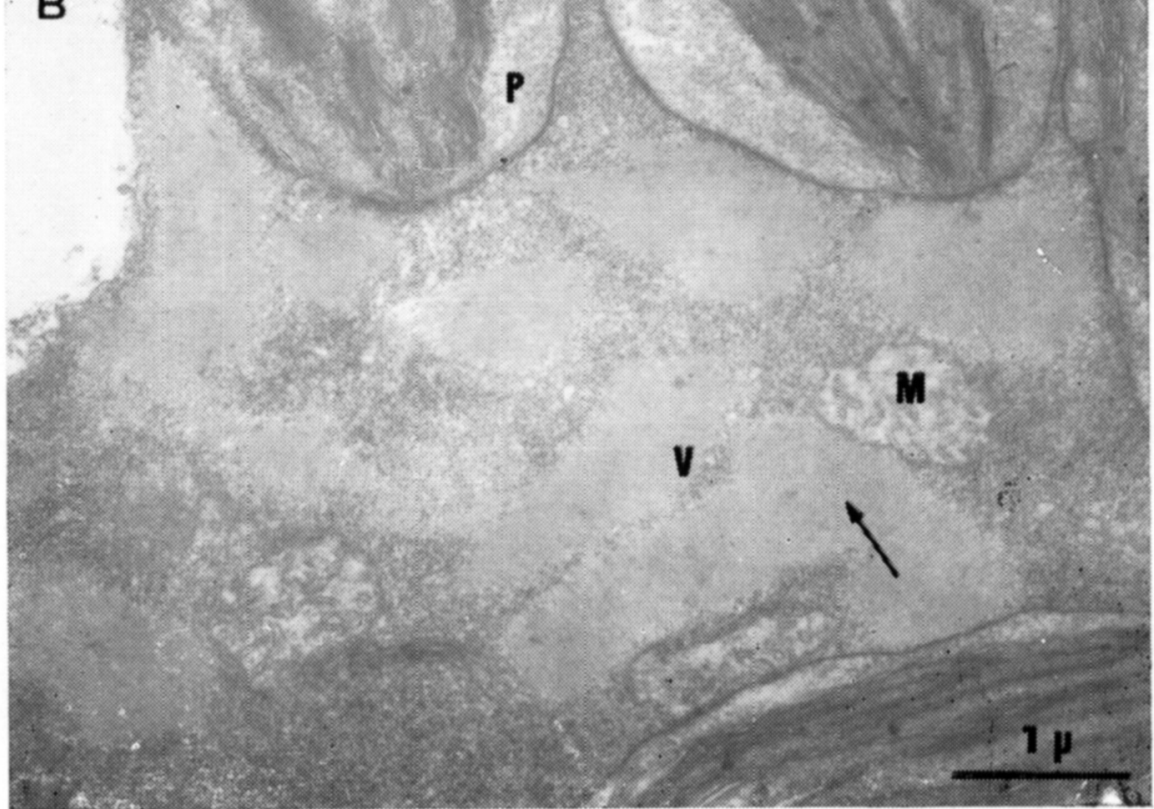

A e B - Grupo de partículas do VLC, dispostas em formação espiralada. A seta cm B indica na zona central da espiral um arranjo cristalino das partículas, seccionadas transversalmente. $\quad \mathbf{M}$ - mitocôndrio; $\mathbf{P}$ - cloroplasto. 


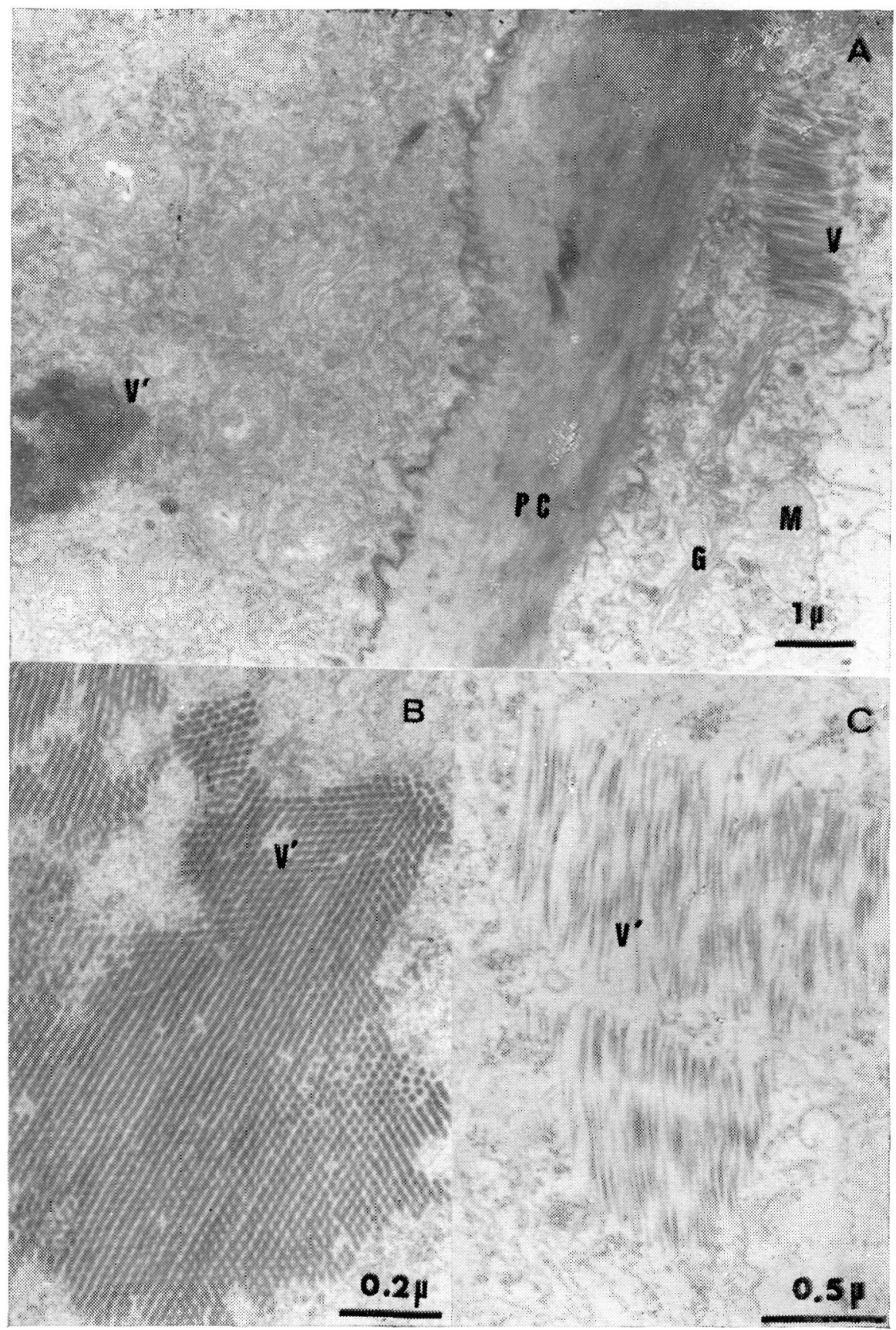

A - Micrografia electrônica, a baixa magnificaç̃o, de parte da célula epidérmica e do córtex adjacente, em ráz de couve, infetada pelo VLC. $\mathrm{Na}$ epiderme nota-se um grupo de partículas seccionadas longitudinalmente (V), e no córtex, outro, seccionadas transversalmente $\left(\mathbf{V}^{\prime}\right)$ e mostrando um arranjo cristalino. O diâmetro destas úitimas é ligeiramente maior que as partículas consideradas VLC. PC - parede celular. M - mitocôndrio; G - complexo de Golgi. B - Detalhe do arranjo cristalino de A. C - Secção Iongitudinal das partículas grossas ( $\left.\mathbf{V}^{\prime}\right)$. 


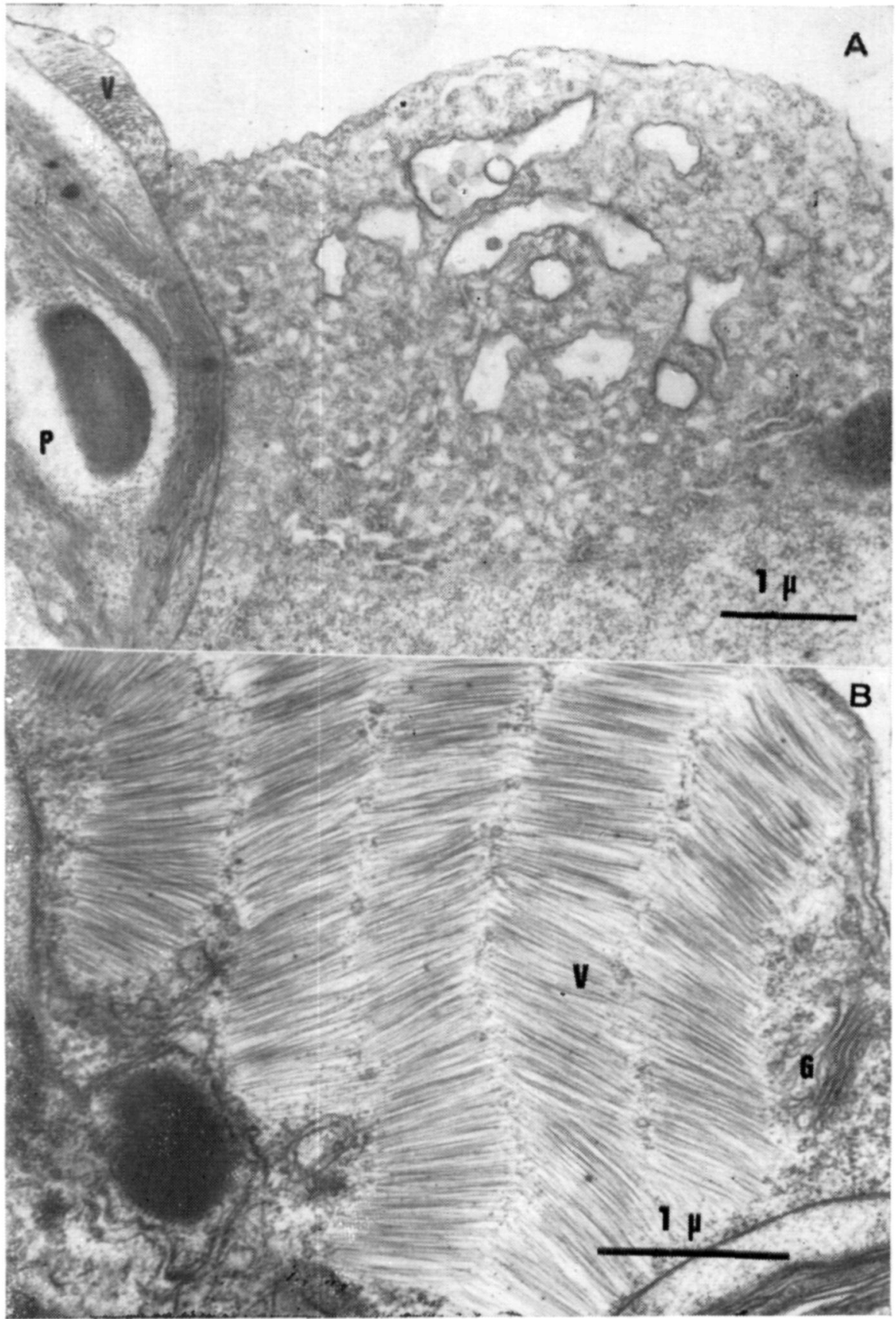

A - Zona vesiculada e rica em ribosoma, no citoplasma de uma célula foliar. Um pequeno agregado do VLC (V) pode ser notado próximo ao cloroplasto (P). B - Partículas do VLC (V) formando uma inclusão em que elas aparecem dispostas em várias camadas sobrepostas. Dentro de cada camada as partículas têm comprimento bastante uniforme e aproximadamente igual ao seu comprimento normal. G - Complexo de Golgi. 